\title{
What Doctors Wish They Knew: Treatment Compliance in an Online Health Community for Chronic Patients
}

\author{
Ermira Zifla \\ University of New Hampshire \\ ermira.zifla@unh.edu
}

\author{
Sunil Wattal \\ Temple University \\ swattal@temple.edu
}

\begin{abstract}
Treatment compliance for patients with chronic health problems is important for the management of their illness due to the long-term nature of their conditions. In this study, we examine how evaluations of different types of treatments provided by members of an online health community are associated with treatment evaluations and compliance. We use selfreported data on evaluation and compliance of over 270 different treatments from over 20,000 patients in a prominent online health community. We find that other community members' treatment evaluation valence is positively associated with patient treatment evaluation and treatment compliance. Similarly, other community members' treatment compliance is positively associated with patient treatment compliance. We also find these relations are moderated by community size and ratings variance. We discuss the theoretical implications of these results for the online health communities' literature, as well as the practical implications for patients, healthcare providers, and policy makers.
\end{abstract}

\section{Introduction}

The Internet is changing how people learn about and cope with chronic illness. Chronic diseases account for $86 \%$ of total healthcare costs and are the leading cause of death and disability in the United States [1]. Chronic diseases involve a recurring condition, usually associated with other health complications, impairment and disability [2]. Given the increase in popularity of Web 2.0. technologies, many patients with chronic health problems participate in online health communities for informational and social support [3]. Participation in online health communities enables patients to become not only consumers but also producers of health-related information. In these communities, patients share information about their experience with the illness such as their symptoms, their treatments, and how the illness affects their quality of life. Despite advances in Web 2.0. technologies, treatment compliance remains one of the main challenges for both doctors and patients of chronic health conditions. Research shows that approximately $50 \%$ of patients do not take medications as prescribed [4] and treatment noncompliance is associated with illness relapse and increased healthcare costs [5].

The Health Belief Model (HBM) is one of the first models to explain how individuals make health-related decisions [6]. Accordingly, factors that affect compliance include patients' beliefs about the treatment, risks and benefits associated with the treatment, and barriers to the treatment [5], [6]. The literature on compliance has shown that compliance is lower in the presence of side effects, long treatment periods, complex treatment regimens and mental health disorders [7]. Research has further shown that treatment beliefs are more powerful predictors to treatment compliance than clinical or sociodemographic factors [8].

Past research has examined the influence of social media in shaping consumer behavior. For example, online ratings affect users' consumption of different types of products and services, e.g., books [9], movies [10] and restaurants [11]. However, online ratings for credence goods - goods whose quality is difficult to assess even after use (e.g., treatments) [12] — have not received much attention. Some studies have provided empirical evidence on the importance of offline family and social support on treatment compliance [13]. However, it is not clear how patients make treatment decisions in the presence of Web 2.0. technologies that allow patients to connect with others, and obtain word of mouth regarding these treatments.

In this study, we examine how patients' postadoption treatment evaluation and treatment compliance are related with community members' ratings about the treatment. Participating in an online health community may help patients discover new 
treatments from other patients with similar conditions. The online community may also exert social influence over the patient's perception of a treatment. Previous studies have found evidence of social influence even when people are not aware of it [14]. However, the effects of other online community members' opinions on one's perception about a treatment are not straightforward. Moreover, the extent to which patients are connected with other community members might also affect their perceptions about the treatment.

With this motivation, we address the following research questions:

1. How do online community members' treatment evaluation affect patients' treatment evaluation and compliance?

2. How does community size and variance moderate the effect of community members' treatment evaluation on patients' treatment compliance?

To answer the research questions, we analyze data from a popular online health community. We examine how treatment ratings in an online health community are associated with patients' evaluation of a treatment for a wide range of treatments evaluated by patients with chronic healthcare problems. We find that online community members' ratings of a treatment are positively associated with a focal patient's evaluation of a treatment. We also find that other community members' compliance is positively associated with a patient's treatment compliance. These relationships are moderated by community size and ratings variance.

The results of this study contribute to the literature on online communities by offering empirical evidence of the effects of community participation in a healthcare context. The study also contributes to the emerging literature on online health communities by focusing on the effects of digital cues provided by other community members on patients' compliance with treatment in the case of chronic illnesses. Finally, the results of this study also have practical implications for patients and healthcare providers.

The paper is organized as follows: In the next section, we provide a brief overview of two streams of related literature: online word of mouth and online health communities. We continue with a description of the research model and proposed hypotheses. Next, we describe the research method and empirical estimation on data from an online health community. Finally, we discuss the theoretical and managerial implications and conclude with limitations, and directions for future research

\section{Literature Review}

\subsection{Online Word-of-Mouth}

Online reviews are a representation of usergenerated content and consumer word of mouth. Scholars have long investigated consumer motivations for word of mouth (WOM). A classic study [15] found consumers can be motivated by a strong feeling about a product (product-involvement), a desire to gratify certain emotional needs (self-involvement), a wish to help other consumers (other-involvement) or by advertisements or other communications (messageinvolvement). Research has also examined the specific motivations behind posting online reviews [16], [17]. Reviewers seek both notoriety, as they are more likely to review lesser-known products, and community, as they are also more likely to review products that are more popular, and that have already received a large number of reviews [16].

Online reviews are considered an important source of information for consumer decision-making [9], [18], [19]. Research on online reviews has shown that diagnostic reviews written by credible reviewers are helpful for consumers [20]. The perceived helpfulness of an online review is affected by review length, emotion, and rating [18], [21]. A large body of work in this area has examined the relationship between online reviews and sales. Previous studies have shown that the volume and valence of online reviews significantly impact sales of various products [9], [22]-[24]. Other studies have also looked at the impact of affective content of the reviews on conversion rates [25]. Studies have shown that review ratings negatively affect hotel bookings [26] and variance in brand ratings is significantly associated with firm value [27]. Studies have also examined multiple mediating factors for the relationship between word of mouth and sales including product type and consumer attributes [17].

\subsection{Online Health Communities}

A growing research stream is examining the impact of social networks on patients' health outcomes. Previous studies on online health communities have argued that patients seek both informational support and social support in these communities [3]. Patients are willing to share personal health information in online health communities because they receive personal benefits such as create new social ties and obtain knowledge despite their privacy concerns [28]. Patients' social connections in online health communities are affected by their health-related traits as people tend to find similar others to establish 
connections [29]. Many studies on online health communities are limited to small communities focused only on one type of disease, for example, a community for patients with Parkinson's disease [30] and a community for diabetes patients [31]. Studies have documented that an individual's health is connected to the health of other socially connected individuals [32].

\section{Hypotheses}

Based on a rich body of literature regarding compliance in healthcare and online ratings we argue how online community ratings are associated with patient treatment evaluation and compliance. There have been two main perspectives in the healthcare literature that explain patience compliance behavior. The first perspective focuses on the patient-doctor relationship and argues that compliance is higher when doctors give clear instructions on the treatment regimen [33]. The second perspective focuses on the patient, and stipulates that a patient's beliefs about the treatment will affect compliance [34]. In this study, we adopt the second perspective, which emphasizes the importance of patients' beliefs and perceptions about the treatment in explaining compliance.

\subsection{The Health Belief Model}

The Health Belief Model (HBM) provides one the main frameworks that relate patients' beliefs with health-related behavior [34]. The original HBM was concerned with preventive health behaviors in the absence of symptoms. According to the Health Behavior Model, patients conduct a risk-benefit analysis before making health-related decisions. Patients evaluate the susceptibility to the disease, perceived threats and perceived benefits of preventive actions before taking the recommended preventive health action [34].

Patients' beliefs about their treatment are related to compliance behavior for chronic illness. According to the Theory of Reasoned Action, individuals' decisions to engage in a behavior will depend on their preexisting attitudes and behavioral intentions [35]. Therefore, patients' beliefs about the effectiveness of a treatment will be positively associated with their compliance behavior. Expanding on the HBM, which mainly focused on acute conditions, studies have linked patients' beliefs about their treatment to compliance behavior for chronic illnesses. Accordingly, patient beliefs about the necessity of their treatment are positively related with compliance, while concerns about their treatment are negatively related with compliance [8]. Therefore, we expect the overall relationship between patient evaluation and compliance to be positive.

$\mathrm{H} 1$ : Patient evaluation is positively associated with patient compliance.

\subsection{Community Ratings Valence}

Kasl [36] argued for the need to extend HBM to the context of chronic healthcare patients. In addition to patients' own beliefs about the treatment, previous studies have argued that other people's opinions about treatments affect their behavior. For example, $\mathrm{n}$ the context of chronic healthcare patients, HBM has been extended to explain how mothers' beliefs affect children's compliance with treatment for diabetes [37] and asthma [38] patients. These studies provided the first steps in linking other people's beliefs to patients' compliance. The widespread use of Web 2.0. technologies has helped patients connect with others who have similar illnesses. Patients can discuss their opinions and experiences with different treatments with other community members. Now, patients' beliefs and opinions about their treatments are also likely to be affected by the opinions of others who are not their immediate family. Therefore, patients who participate in health online communities are likely to be affected by other community members' evaluations. Additionally, community members' healthcare decisions may affect patients' health-related behavior.

$\mathrm{H} 2$ : Community evaluation is positively associated with patient evaluation.

H3: Community compliance is positively associated with patient compliance.

\subsection{Community Ratings Variance}

Ratings variance can potentially reveal additional information to the ratings valence. In the context of online product reviews, Sun [39] finds that average high valence is associated with high product quality, whereas high variance is associated with a niche product-one that is subject to polarized opinions. Therefore, the impact of ratings variance depends on ratings valence. Higher ratings variance on products is associated with higher product demand if the average ratings are low [39].

In a healthcare context, where patients rate different treatments, if the ratings variance for treatment evaluations is high, it means that there is a lack of consensus among the patients regarding the perceived benefits of the treatments. This lack of consensus among the patients can be attributed to individual heterogeneity regarding the treatment or is a signal of treatment quality. If the source of this discordance is the individual heterogeneity regarding the treatment, 
then high variance could mean that the treatment's effect varies greatly among different patients, meaning that it is a "niche" treatment. High ratings variance could also be a signal that the ratings are not trustworthy, therefore they can negatively affect patients' evaluations. Therefore, we expect that ratings variance mitigates the effect of community ratings valence on treatment evaluation and compliance.

H4: The positive relationship between community evaluation and patient evaluation is negatively moderated (weaker) when community evaluation variance is high.

H5: The positive relationship between community compliance and patient compliance is negatively moderated (weaker) when community compliance variance is high.

\subsection{Community Size}

Consumer product ratings are subject to social influence from other consumers' product ratings [40]. Ratings volume (the number of ratings) affects the effect of ratings valence on consumer decision making such that high ratings volume accentuates the perception of positivity in ratings[41]. In the context of an online health community, we hypothesize that community size is a moderator between community evaluation (or compliance) and patient evaluation (or compliance). The intuition is that the larger the size of the community, more credible is the signal that it provides [42]. High ratings volume increase the preference for a product that has positive valence while decreasing the preference for a product with negative valence [41], [43].

H6: The interaction between community evaluation and community size is positively associated with patient evaluation.

H7: The interaction between community compliance and community size is positively associated with patient evaluation.

Figure 1 shows the research model and the proposed associations among the constructs.

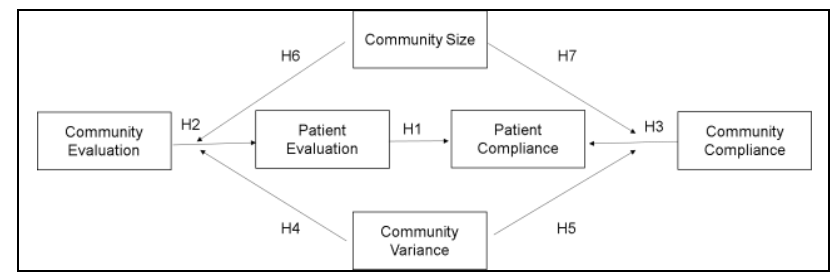

Figure 1. Research model

\section{Methodology}

\subsection{Data Collection and Description}

We collected data from a public prominent online health community. This community counts over 500,000 members who have over 2,500 different chronic health conditions. Patients can become members of the community and create a personal page on the community website where they can report their illnesses, treatments and progress. Moreover, community members and website visitors can browse all the treatments reported by all the patients in the community and view the reported treatment evaluations. Treatments are categorized into groups. Examples include prescription drugs, supplements, equipment and lifestyle modifications.

We collected data using a Java-based web crawler. The crawler retrieved information about patients' evaluations for 271 treatments. A total number of 21,269 patients evaluated the treatments in our dataset. $32 \%$ of the patients have only one treatment evaluation, while the rest have evaluated more than one treatment. Each patient evaluates one treatment only once. The patients evaluated the perceived treatment effectiveness, the treatment side effects, difficulty of taking the treatment as prescribed and treatment compliance. Additionally, each patient also reported the treatment start date. Table 1 shows the questions and scales used to measure the variables for treatment evaluation and treatment compliance. The questions and scales used to measure treatment evaluations are developed by the community website and presented to each patient when they decide to report a treatment evaluation.

Table 1. Variable description

\begin{tabular}{|l|l|}
\hline \multicolumn{1}{|c|}{$\begin{array}{c}\text { Variable } \\
\text { name }\end{array}$} & \multicolumn{1}{c|}{ Variable description } \\
\hline Effectiveness & $\begin{array}{l}\text { Measures perceived treatment } \\
\text { effectiveness on a scale 1-5 using the } \\
\text { question "Currently, how effective is this } \\
\text { treatment?" }\end{array}$ \\
\hline Side Effects & $\begin{array}{l}\text { Measures treatment side effects on a } \\
\text { scale 1-4 using the question "Currently, } \\
\text { how are the overall side effects of this } \\
\text { treatment?" }\end{array}$ \\
\hline Burden & $\begin{array}{l}\text { Measures treatment burden on a scale } \\
1-4 \text { using the question "How difficult is it } \\
\text { for you to take this treatment as } \\
\text { prescribed?" }\end{array}$ \\
\hline $\begin{array}{l}\text { Patient } \\
\text { Compliance }\end{array}$ & $\begin{array}{l}\text { Measures treatment compliance on a } \\
\text { how often do you take the treatment as } \\
\text { prescribed?" }\end{array}$ \\
\hline $\begin{array}{l}\text { Patient } \\
\text { Evaluation }\end{array}$ & $\begin{array}{l}\text { The average of treatment effectiveness, } \\
\text { treatment side effects (reverse coded) } \\
\text { and treatment burden (reverse coded). }\end{array}$
\end{tabular}


Table 1. Variable description (continued)

\begin{tabular}{|l|l|}
\hline $\begin{array}{l}\text { Community } \\
\text { Evaluation }\end{array}$ & $\begin{array}{l}\text { The average of patient evaluation for all } \\
\text { the patients who have evaluated the } \\
\text { treatment before the patient. }\end{array}$ \\
\hline $\begin{array}{l}\text { Community } \\
\text { Compliance } \\
\text { all the patients who have reported the } \\
\text { treatment compliance before the } \\
\text { patient. }\end{array}$ \\
\hline $\begin{array}{l}\text { Community } \\
\text { Valuation }\end{array}$ & $\begin{array}{l}\text { The standard deviation of patient } \\
\text { evaluation for all the patients who have } \\
\text { evaluated the treatment before the } \\
\text { patient. }\end{array}$ \\
\hline $\begin{array}{l}\text { Community } \\
\text { Vompliance }\end{array}$ & $\begin{array}{l}\text { The standard deviation of patient } \\
\text { compliance for all the patients who } \\
\text { have reported the treatment } \\
\text { compliance before the patient. }\end{array}$ \\
\hline $\begin{array}{l}\text { Community } \\
\text { Size }\end{array}$ & $\begin{array}{l}\text { The number of patients who have } \\
\text { evaluated the treatment before the } \\
\text { patient. }\end{array}$ \\
\hline $\begin{array}{l}\text { Treatment } \\
\text { Category }\end{array}$ & $\begin{array}{l}\text { 1=Prescription Drug, 2=Other (e.g., } \\
\text { over the counter, supplements, diet, } \\
\text { exercise) }\end{array}$ \\
\hline $\begin{array}{l}\text { Treatment } \\
\text { Duration }\end{array}$ & $\begin{array}{l}\text { The difference between treatment start } \\
\text { date and treatment evaluation date } \\
\text { (days) }\end{array}$ \\
\hline
\end{tabular}

- Measures: We calculated the patient treatment evaluation by averaging treatment effectiveness, treatment side effects (reverse coded) and treatment burden (reverse coded). We calculated community treatment evaluation for a patient as the average evaluation of all the patients who evaluated a treatment before the patient evaluation. Similarly, we calculated community compliance as the average compliance of all the patients who have reported their compliance before the patient. Community size is calculated as the total number of patients who have evaluated a treatment. See table 2 for descriptive statistics and table 3 for correlations of the variables used in the model.

Table 2: Descriptive Statistics

\begin{tabular}{|l|c|c|c|c|}
\hline \multicolumn{1}{|c|}{ Variable } & Mean & Std. dev. & Min & Max \\
\hline Patient Evaluation & 3.391 & 0.708 & 1 & 4.333 \\
\hline $\begin{array}{l}\text { Community } \\
\text { Evaluation }\end{array}$ & 3.379 & 0.277 & 1 & 4.333 \\
\hline $\begin{array}{l}\text { Patient } \\
\text { Compliance }\end{array}$ & 3.548 & 0.817 & 1 & 4 \\
\hline $\begin{array}{l}\text { Community } \\
\text { Compliance }\end{array}$ & 3.576 & 0.214 & 1 & 4 \\
\hline $\begin{array}{l}\text { Community } \\
\begin{array}{l}\text { Evaluation } \\
\text { Variance }\end{array}\end{array}$ & 0.173 & 0.107 & 0 & 1.061 \\
\hline $\begin{array}{l}\text { Community } \\
\text { Compliance } \\
\text { Variance }\end{array}$ & 0.743 & 0.158 & 0 & 1.730 \\
\hline Community Size & 329.486 & 323.345 & 2 & 1843 \\
\hline $\begin{array}{l}\text { Treatment } \\
\text { Category }\end{array}$ & 1.197 & 0.397 & 1 & 2 \\
\hline $\begin{array}{l}\text { Treatment } \\
\text { Duration }\end{array}$ & 1190.81 & 1851.807 & 0 & 18150 \\
\hline
\end{tabular}

$N=41,368$
Table 3: Correlations

\begin{tabular}{|c|c|c|c|c|c|c|c|c|c|}
\hline & Variable & 1 & 2 & 3 & 4 & 5 & 6 & 7 & 8 \\
\hline 1 & $\begin{array}{l}\text { Patient } \\
\text { Evaluation }\end{array}$ & $\begin{array}{c}1.00 \\
0\end{array}$ & & & & & & & \\
\hline 2 & $\begin{array}{l}\text { Community } \\
\text { Evaluation }\end{array}$ & $\begin{array}{c}0.30 \\
7\end{array}$ & $\begin{array}{l}1.0 \\
00\end{array}$ & & & & & & \\
\hline 3 & $\begin{array}{l}\text { Patient } \\
\text { Compliance }\end{array}$ & $\begin{array}{c}0.19 \\
4\end{array}$ & $\begin{array}{l}(0 . \\
04 \\
4)\end{array}$ & 1.000 & & & & & \\
\hline 4 & $\begin{array}{l}\text { Community } \\
\text { Compliance }\end{array}$ & $\begin{array}{l}(0.06 \\
1)\end{array}$ & $\begin{array}{l}(0 . \\
17 \\
7)\end{array}$ & 0.193 & $\begin{array}{c}1.00 \\
0\end{array}$ & & & & \\
\hline 5 & $\begin{array}{l}\text { Community } \\
\text { Evaluation } \\
\text { Variance }\end{array}$ & $\begin{array}{c}(0.05 \\
9)\end{array}$ & $\begin{array}{l}(0 . \\
16 \\
0)\end{array}$ & 0.010 & $\begin{array}{c}0.03 \\
1\end{array}$ & $\begin{array}{c}1.00 \\
0\end{array}$ & & & \\
\hline 6 & $\begin{array}{l}\text { Community } \\
\text { Compliance } \\
\text { Variance }\end{array}$ & $\begin{array}{c}0.03 \\
6\end{array}$ & $\begin{array}{l}0.0 \\
53\end{array}$ & $(0.132)$ & $\begin{array}{l}(0.7 \\
40)\end{array}$ & $\begin{array}{l}(0.0 \\
61)\end{array}$ & $\begin{array}{c}1.00 \\
0\end{array}$ & & \\
\hline 7 & $\begin{array}{l}\text { Community } \\
\text { Size }\end{array}$ & $\begin{array}{c}0.02 \\
6\end{array}$ & $\begin{array}{l}(0 . \\
06 \\
5)\end{array}$ & 0.031 & $\begin{array}{c}0.15 \\
1\end{array}$ & $\begin{array}{l}(0.4 \\
00)\end{array}$ & $\begin{array}{l}(0.0 \\
51)\end{array}$ & $\begin{array}{l}1.0 \\
00\end{array}$ & \\
\hline 8 & $\begin{array}{l}\text { Treatment } \\
\text { Category }\end{array}$ & $\begin{array}{c}0.06 \\
5\end{array}$ & $\begin{array}{l}0.2 \\
35\end{array}$ & $(0.116)$ & $\begin{array}{l}(0.4 \\
34)\end{array}$ & $\begin{array}{l}(0.0 \\
88)\end{array}$ & $\begin{array}{c}0.22 \\
4\end{array}$ & $\begin{array}{l}(0 . \\
24 \\
5)\end{array}$ & $\begin{array}{c}1 . \\
00 \\
0\end{array}$ \\
\hline 9 & $\begin{array}{l}\text { Treatment } \\
\text { Duration (In) }\end{array}$ & $\begin{array}{c}0.14 \\
6\end{array}$ & $\begin{array}{l}0.0 \\
83\end{array}$ & $(0.007)$ & $\begin{array}{l}(0.0 \\
37)\end{array}$ & $\begin{array}{l}(0.0 \\
66)\end{array}$ & $\begin{array}{c}0.02 \\
6\end{array}$ & $\begin{array}{l}0.0 \\
98\end{array}$ & $\begin{array}{c}0 . \\
01 \\
1\end{array}$ \\
\hline
\end{tabular}

\section{Results}

Table 4 summarizes the results of a fixed effects regression model [44] for the effects of community variables on treatment evaluation and compliance with individual and time fixed effects.

We find that the coefficient of Patient Evaluation in column 4 is 0.231 and significant at $p<0.01$, suggesting that Patient Evaluation is positively associated with Compliance. This provides support for hypothesis H1. We also find that the coefficient of Community Evaluation in column 2 is 0.757 and significant at $p<0.01$, suggesting that Community Evaluation is positively associated with Patient Evaluation. This provides support for hypothesis H2. We find a significant interaction of Community Evaluation and the Community Evaluation Variance (coefficient $=-0.459, \mathrm{p}<0.01$. This suggests that when Community Evaluation is low, higher variance is associated with higher Patient Evaluation. Also, when Community Evaluation is high, higher variance is associated with lower Patient Evaluation. This provides support for hypothesis $\mathrm{H} 4$. We also find a significant interaction of Community Evaluation and Community Size (coefficient $=0.0002, p<0.01$. This suggests that when Community Evaluation is low, higher Community Size is associated with lower Patient Evaluation. Also, when Community Evaluation is high, higher Community Size is associated with higher Patient Evaluation. Table 4 summarizes the results of a fixed effects regression model [44] for the effects of community variables on treatment evaluation and compliance with individual and time fixed effects.

We find that the coefficient of Patient Evaluation in column 4 is 0.231 and significant at $p<0.01$, 
suggesting that Patient Evaluation is positively associated with Compliance. This provides support for hypothesis $\mathrm{H} 1$. We also find that the coefficient of Community Evaluation in column 2 is 0.757 and significant at $p<0.01$, suggesting that Community Evaluation is positively associated with Patient Evaluation. This provides support for hypothesis $\mathrm{H} 2$. We find a significant interaction of Community Evaluation and the Community Evaluation Variance (coefficient $=-0.459, \mathrm{p}<0.01$. This suggests that when Community Evaluation is low, higher variance is associated with higher Patient Evaluation. Also, when Community Evaluation is high, higher variance is associated with lower Patient Evaluation. This provides support for hypothesis H4. We also find a significant interaction of Community Evaluation and Community Size (coefficient $=0.0002, \mathrm{p}<0.01$. This suggests that when Community Evaluation is low, higher Community Size is associated with lower Patient Evaluation. Also, when Community Evaluation is high, higher Community Size is associated with higher Patient Evaluation. This provides support for hypothesis H6.

We also find support for Hypothesis H3 because the coefficient of Community Compliance in column 4 is 0.915 and significant at $\mathrm{p}<0.01$, suggesting that Community Compliance is positively associated with Patient Compliance. We find a significant interaction of Community Compliance and Community Compliance Variance (coefficient $=-0.302, \mathrm{p}<0.01$. This suggests that when Community Compliance is low, higher variance is associated with higher Compliance. Also, when Community Compliance is high, higher variance is associated with higher Compliance. This provides support for hypothesis H5. We also find a significant interaction of Community Compliance and Community Size (coefficient=0.0005, $\mathrm{p}<0.01$. This suggests that when Community Compliance is low, higher Community Size is associated with lower Compliance. Also, when Community Compliance is high, higher Community Size is associated with higher Compliance. This provides support for hypothesis $\mathrm{H} 7$.

Overall, the results show that in larger communities, community evaluation and patient evaluation are positively associated more strongly than in smaller communities. Also, when evaluations have larger variance, community evaluation is associated less strongly with patient evaluation than when evaluations have smaller variance.

\section{Table 4: Estimation Results- The Effect of Online Community on Treatment evaluation and Compliance}

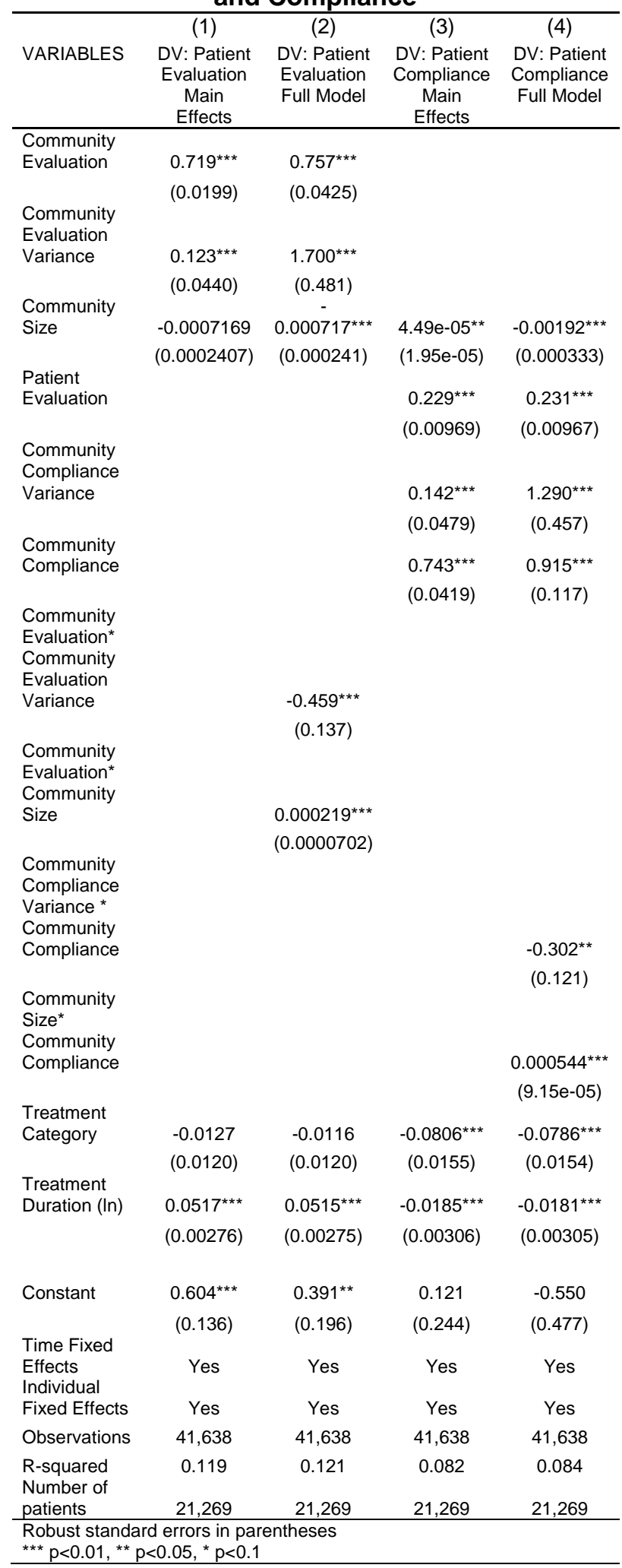




\section{Discussion and Conclusion}

In this study, we examined the effects of online ratings for treatment evaluations in an online health community on treatment evaluations and treatment compliance for patients with chronic health conditions. The results of the study show that community ratings for treatments are positively associated with patient treatment evaluation and compliance. These effects are moderated by community size and online ratings variance. In larger communities, the association between online community ratings and patient evaluations and compliance is amplified. Also, when the ratings variance is high, the association between online community ratings and patient evaluations and compliance is weaker.

This study contributes to the broader literature on the effects of IT on healthcare [45] by providing an empirical assessment of the effects of online treatment ratings for chronic health patients. Also, the study contributes to the emerging literature on online health communities [3], [29]by focusing on a large community of patients with different types of chronic health conditions. The results of this study also bear important implications for patients, healthcare practitioners and online health community designers. Based on our results, patients might consider "niche" treatments with higher treatment ratings variance if they are suffering from conditions that are difficult to diagnose. This study also emphasizes the role of patients as active decision makers regarding their health behavior, departing from traditional compliance literature that generally assumes the patient is a passive recipient of instructions from their doctor [7]. Nevertheless, healthcare providers might gain insights from the online community and recommend treatments that are rated low on average but have a high ratings variance to "zebra" patients, who have rare conditions.

This study has several limitations. First, the data used is observational, and it is possible that the results reflect homophilic tendencies among community members in addition to social influence [46]. In order to address this shortcoming, the study could be enhanced by conducting a randomized experiment where patients are asked to evaluate different treatments but only a subsample of them receives information about the evaluations of other community members. Second, the treatment evaluation data is selfreported by the patients. There have been concerns about the accuracy of patient self-reported health data as patients may report information that is not truthful [47]. However, the data for this study comes from a prominent online health community and the issue of falsely reported data is at odds with the longevity and size of the online community. Finally, there are relatively few seniors (age 75+) in the online community, which is not a representation of the general population. These limitations notwithstanding, we believe that study represents an important first step in understanding for technology mechanisms such as online social communities play a key role in shaping behavior of patients towards better compliance for treatment of chronic conditions.

To conclude, participation in an online health community has important implications on treatment evaluations for community members. Future research might further investigate how the network position (e.g., betweenness, centrality) affects patients' perceptions about the treatment. Another promising extension is related to the objectives of patients' activities in the online community. For example, patients may join online health communities to socialize with other patients, to look for relevant information about their disease, or to simply keep a diary of symptoms and treatments for their own use. Understanding how the patients' objectives affect their online activities, and subsequently their perceptions about their treatment will help online health communities customize their website to better meet patients' requirements. Although these important questions are difficult to address in this study's setting, future studies can conduct behavioral experiments which will provide valuable data to answer these questions.

\section{References}

[1] CDC, "Chronic Disease Overview | Publications | Chronic Disease Prevention and Health Promotion | CDC," 28-Jun-2017. [Online]. Available:

https://www.cdc.gov/chronicdisease/overview/index.htm. [Accessed: 07-Jul-2017].

[2] S. Bernell and S. W. Howard, "Use Your Words Carefully: What Is a Chronic Disease?," Front Public Health, vol. 4, Aug. 2016.

[3] L. Yan and Y. Tan, "Feeling Blue? Go Online: An Empirical Study of Social Support Among Patients," Information Systems Research, vol. 25, no. 4, pp. 690-709, Dec. 2014.

[4] M. T. Brown and J. K. Bussell, "Medication Adherence: WHO Cares?," Mayo Clin Proc, vol. 86, no. 4, pp. 304-314, Apr. 2011.

[5] D. O. Perkins, "Predictors of noncompliance in patients with schizophrenia.," The Journal of clinical psychiatry, 2002 . 
[6] M. H. Becker and L. A. Maiman, "Sociobehavioral determinants of compliance with health and medical care recommendations," Medical care, pp. 10-24, 1975.

[7] P. Conrad, "The meaning of medications: another look at compliance," Social science \& medicine, vol. 20, no. 1, pp. 29-37, 1985 .

[8] R. Horne and J. Weinman, "Patients' beliefs about prescribed medicines and their role in adherence to treatment in chronic physical illness," Journal of Psychosomatic Research, vol. 47, no. 6, pp. 555-567, Dec. 1999.

[9] J. A. Chevalier and D. Mayzlin, "The Effect of Word of Mouth on Sales: Online Book Reviews," Journal of Marketing Research (JMR), vol. 43, no. 3, pp. 345-354, Aug. 2006.

[10] Y. Liu, "Word of mouth for movies: Its dynamics and impact on box office revenue," Journal of marketing, vol. 70, no. 3, pp. 74-89, 2006.

[11] X. Lu, S. Ba, L. Huang, and Y. Feng, "Promotional marketing or word-of-mouth? Evidence from online restaurant reviews," Information Systems Research, vol. 24, no. 3, pp. 596-612, 2013.

[12] M. R. Darby and E. Karni, "Free competition and the optimal amount of fraud," The Journal of law and economics, vol. 16, no. 1, pp. 67-88, 1973.

[13] T. A. Miller and M. R. DiMatteo, "Importance of family/social support and impact on adherence to diabetic therapy," Diabetes Metab Syndr Obes, vol. 6, pp. 421-426, Nov. 2013.

[14] A. D. I. Kramer, J. E. Guillory, and J. T. Hancock, "Experimental evidence of massive-scale emotional contagion through social networks," PNAS, vol. 111, no. 24, pp. 8788-8790, Jun. 2014.

[15] E. Dichter, "How Word-of-Mouth Advertising Works," Harvard Business Review, vol. 44, no. 6, p. 147, Dec. 1966.

[16] C. Dellarocas, G. (Gordon) Gao, and R. Narayan, “Are Consumers More Likely to Contribute Online Reviews for Hit or Niche Products?," Journal of Management Information Systems, vol. 27, no. 2, pp. 127-157, Fall 2010.

[17] T. Hennig-Thurau, K. P. Gwinner, G. Walsh, and D. D. Gremler, "Electronic word-of-mouth via consumer-opinion platforms: What motivates consumers to articulate themselves on the Internet?," Journal of interactive marketing, vol. 18, no. 1, pp. 38-52, 2004.

[18] S. M. Mudambi and D. Schuff, "What Makes a Helpful Online Review? A Study of Customer Reviews on Amazon.com," MIS Quarterly, vol. 34, no. 1, pp. 185-200, Mar. 2010.
[19] N. Archak, A. Ghose, and P. G. Ipeirotis, "Deriving the Pricing Power of Product Features by Mining Consumer Reviews," Management Science, vol. 57, no. 8, pp. 14851509, Jun. 2011.

[20] D. Weathers, S. D. Swain, and V. Grover, "Can online product reviews be more helpful? Examining characteristics of information content by product type," Decision Support Systems, vol. 79, pp. 12-23, Nov. 2015.

[21] D. Yin, S. D. Bond, and H. Zhang, "Anxious or Angry? Effects of Discrete Emotions on the Perceived Helpfulness of Online Reviews 1," MIS Quarterly, vol. 38, no. 2, pp. 539560, Jun. 2014.

[22] A. Babić Rosario, F. Sotgiu, K. De Valck, and T. H. Bijmolt, "The effect of electronic word of mouth on sales: A meta-analytic review of platform, product, and metric factors," Journal of Marketing Research, vol. 53, no. 3, pp. 297-318, 2016.

[23] B. Gu, J. Park, and P. Konana, "Research Note-The Impact of External Word-of-Mouth Sources on Retailer Sales of High-Involvement Products," Information Systems Research, vol. 23, no. 1, pp. 182-196, Apr. 2011.

[24] F. Zhu and X. (Michael) Zhang, "Impact of Online Consumer Reviews on Sales: The Moderating Role of Product and Consumer Characteristics," Journal of Marketing, vol. 74, no. 2, pp. 133-148, Mar. 2010.

[25] S. Ludwig, K. de Ruyter, M. Friedman, E. C. Brüggen, M. Wetzels, and G. Pfann, "More Than Words: The Influence of Affective Content and Linguistic Style Matches in Online Reviews on Conversion Rates," Journal of Marketing, vol. 77, no. 1, pp. 87-103, Jan. 2013.

[26] Q. Ye, R. Law, and B. Gu, "The impact of online user reviews on hotel room sales," International Journal of Hospitality Management, vol. 28, no. 1, pp. 180-182, 2009.

[27] X. Luo, S. Raithel, and M. Wiles, "The Impact of Brand Rating Dispersion on Firm Value," Journal of Marketing Research, vol. 50, pp. 399-415, Jun. 2013.

[28] N. Kordzadeh and J. Warren, "Communicating Personal Health Information in Virtual Health Communities: An Integration of Privacy Calculus Model and Affective Commitment," Journal of the Association for Information Systems, vol. 18, no. 1, p. 45, 2017.

[29] L. (Lucy) Yan, J. Peng, and Y. Tan, "Network Dynamics: How Can We Find Patients Like Us?," Information Systems Research, vol. 26, no. 3, pp. 496-512, Aug. 2015.

[30] S. Venkatesan, W. Han, and R. Sharman, "A Response Quality Model for Online Health Communities," ICIS 2014 Proceedings, Dec. 2014. 
[31] M. Kokkodis and T. Lappas, "Realizing the Activation Potential of Online Communities," 2016.

[32] K. P. Smith and N. A. Christakis, "Social networks and health," Annu. Rev. Sociol, vol. 34, pp. 405-429, 2008.

[33] T. F. Garrity, "Medical compliance and the clinicianpatient relationship: a review," Social Science \& Medicine. Part E: Medical Psychology, vol. 15, no. 3, pp. 215-222, 1981.

[34] L. A. Maiman and M. H. Becker, "The health belief model: Origins and correlates in psychological theory," Health Education Monographs, vol. 2, no. 4, pp. 336-353, 1974.

[35] M. Fishbein and I. Ajzen, Belief, attitude, intention, and behavior: an introduction to theory and research. Reading, Mass.: Addison-Wesley Pub. Co., 1975.

[36] S. V. Kasl, "The Health Belief Model and Behavior Related to Chronic Illness," Health Education Monographs, vol. 2, no. 4, pp. 433-454, Dec. 1974.

[37] M. H. Becker, L. A. Maiman, J. P. Kirscht, D. P. Haefner, and R. H. Drachman, "The Health Belief Model and Prediction of Dietary Compliance: A Field Experiment," Journal of Health and Social Behavior, vol. 18, no. 4, pp. 348-366, 1977.

[38] M. H. Becker, S. M. Radius, I. M. Rosenstock, R. H. Drachman, K. C. Schuberth, and K. C. Teets, "Compliance with a medical regimen for asthma: a test of the health belief model.," Public Health Rep, vol. 93, no. 3, pp. 268-277, 1978.

[39] M. Sun, "How does the variance of product ratings matter?," Management Science, vol. 58, no. 4, pp. 696-707, 2012.
[40] S. Sridhar and R. Srinivasan, "Social Influence Effects in Online Product Ratings," Journal of Marketing, vol. 76, no. 5, pp. 70-88, 2012.

[41] A. Khare, L. I. Labrecque, and A. K. Asare, "The assimilative and contrastive effects of word-of-mouth volume: An experimental examination of online consumer ratings," Journal of Retailing, vol. 87, no. 1, pp. 111-126, 2011.

[42] A. J. Flanagin, M. J. Metzger, R. Pure, A. Markov, and E. Hartsell, "Mitigating risk in ecommerce transactions: perceptions of information credibility and the role of usergenerated ratings in product quality and purchase intention," Electron Commer Res, vol. 14, no. 1, pp. 1-23, Mar. 2014.

[43] W. W. Moe and M. Trusov, "The Value of Social Dynamics in Online Product Ratings Forums," Journal of Marketing Research, vol. 48, no. 3, pp. 444-456, 2011.

[44] C. Hsiao, Analysis of panel data. Cambridge university press, 2014.

[45] R. Agarwal, G. (Gordon) Gao, C. DesRoches, and A. K. Jha, "Research Commentary-The Digital Transformation of Healthcare: Current Status and the Road Ahead," Information Systems Research, vol. 21, no. 4, pp. 796-809, Nov. 2010.

[46] S. Aral, L. Muchnik, and A. Sundararajan,

"Distinguishing influence-based contagion from homophilydriven diffusion in dynamic networks," PNAS, vol. 106, no. 51, pp. 21544-21549, Dec. 2009.

[47] S. A. Newell, A. Girgis, R. W. Sanson-Fisher, and N. J. Savolainen, "The accuracy of self-reported health behaviors and risk factors relating to cancer and cardiovascular disease in the general population 1," American Journal of Preventive Medicine, vol. 17, no. 3, pp. 211-229, Oct. 1999. 